УДК 378. 147

\author{
Куликова Яна Александровна, Пенькова Татьяна Алексеевна
}

\title{
АНАЛИЗ ИСХОДНОГО УРОВНЯ КОМПЬЮТЕРНОЙ ЗАВИСИМОСТИ ОБУЧАЮЩИХСЯ
}

Модернизация современной системы образования, наличие компьютерных технологий-одно из самых ярких событий современности. Практически каждое учебное заведение или организация оснащена компьютером и компьютерными сетями. Активное внедрение компьютерных технологий в повседневную жизнь, безусловно, накладывает определенный отпечаток на формирование и развитие личностных качесть. В представленной статье рассматриваются проблемы интернет-зависимости обучаюиихся, страдаюиих от этой болезни. Описаны результаты диагностирования учащиихс 10-х и 11-х университетских профильных классов Педагогического института ФГБОУ ВО «Тамбовский государственный университет имени Г. Р. Державина» с целью выявления уровня компьютерной зависимости.

Ключевые слова: компьютериая зависимость, социальная адаптация, подростки, интернет.

\section{Yana Kulikova, Tatyana Penkova \\ ANALYSIS OF THE STARTING LEVEL OF COMPUTER DEPENDENCE OF STUDENTS}

Modernization of the modern education system, the availability of computer technology is one of the most striking events of our time. Almost every educational institution or organization is equipped with a computer and computer networks. The active introduction of computer technology in everyday life, of course, leaves a certain imprint on the formation and development of personal qualities. This article discusses the problems of Internet addiction of students suffering from this disease. The results of diagnosing students of the 10th and 11th university profile classes of the Pedagogical Institute of the Federal State Budget Educational Establishment of Higher Education "Tambov State University named after G.R. Derzhavin ", in order to identify the level of computer addiction.

Key words: computer addiction, social adaptation, adolescents, the Internet.

Bвedeниe/Introduction. В настоящее время наблюдается «феномен появления новых видов аддиктивного поведения: уход в виртуальную реальность и интернет-зависимость, зависимость от использования сотового телефона (SMS-зависимость), расстройства, связанные с «фанатизмом〉 вокруг спорта, поп-арта и шоу-бизнеса. В то же время такие нехимические типы зависимого поведения не входят в МКБ, поскольку в этом случае трудно провести четкую грань между нормой и патологией» [11].

Данное исследование посвящено проблеме интернет-зависимости и социальной адаптации подростков, страдающих от этой болезни.

Mamepиалы и методы /Materials and methods. При работе применялись анализ научной и методической литературы по исследуемой теме, сравнение, систематизация, обобщение, наблюдение, анкетирование, тестирование, изучение учебной документации, педагогический эксперимент, методы статистической обработки результатов.

Результаты и обсуждение / Results and discussion. Для определения исходного уровня компьютерной зависимости был проведен констатирующий эксперимент, участниками которого стали: учащиеся 10-х (110 человек) и 11-х (100 человек) университетских профильных классов Педагогического института ФГБОУ ВО «Тамбовский государственный университет имени Г. Р. Державина». 
При сборе необходимого эмпирического материала применялись следующие методики: Скрининговая диагностика компьютерной зависимости (Л. Н. Юрьева, Т. Ю. Больбот); Тест Такера на выявление игровой зависимости; Оценка уровня общительности (В. Ф. Ряховский); Опросник уровня агрессивности Баса - Дарки.

Методика І. Скрининговая диагностика компьютерной зависимости (Л. Н. Юрьева, Т. Ю. Больбот) направлена на выявление уровня компьютерной з॰ависимости. Респонденту предлагается ответить на 11 вопросов. Шкала ответов (от «никогда» до (очень часто») дает возможность определить степень погружения в виртуальный мир.

Обработка результатов проводится в соответствии с ключом. За каждый ответ начисляется от 1 до 4 баллов. Общая оценка подсчитывается путем суммирования баллов. Автор данной методики выделяет следующие уровни выраженности компьютерной зависимости:

до 15 баллов - отсутствие зависимости;

16-22 балла - стадия увлеченности;

23-37 баллов - риск развития компьютерной зависимости;

более 38 баллов - наличие компьютерной зависимости.

По результатам Скрининговой диагностики компьютерной зависимости (Л. Н. Юрьева, Т. Ю. Больбот) было выявлено, что риск развития компьютерной зависимости присутствует у $44 \%$ учащихся 10-х классов и $40 \%$ учащихся $11-\mathrm{x}$ классов. Подростки, имеющие риск развития компьютерной зависимости, более склонны к проведению за компьютером более трех часов в день, у них уменьшается мотивация к учебной деятельности, соответственно падает успеваемость, любимой темой для общения становятся компьютерные игры.

Наличие компьютерной зависимости характерно для 11 \% учащихся 10-х классов и $10 \%$ учащихся 11-х классов. Такие подростки не могут себя контролировать, они эмоционально неустойчивы, если им препятствуют играть в компьютерные игры. Для них характерны повышенная тревожность и возбудимость, рассеянность, рассредоточенность внимания вне игровой деятельности. Наблюдается очень сильное угасание интереса к общению.

Обобщенные результаты диагностики компьютерной зависимости учащихся представлены на рис. 1.

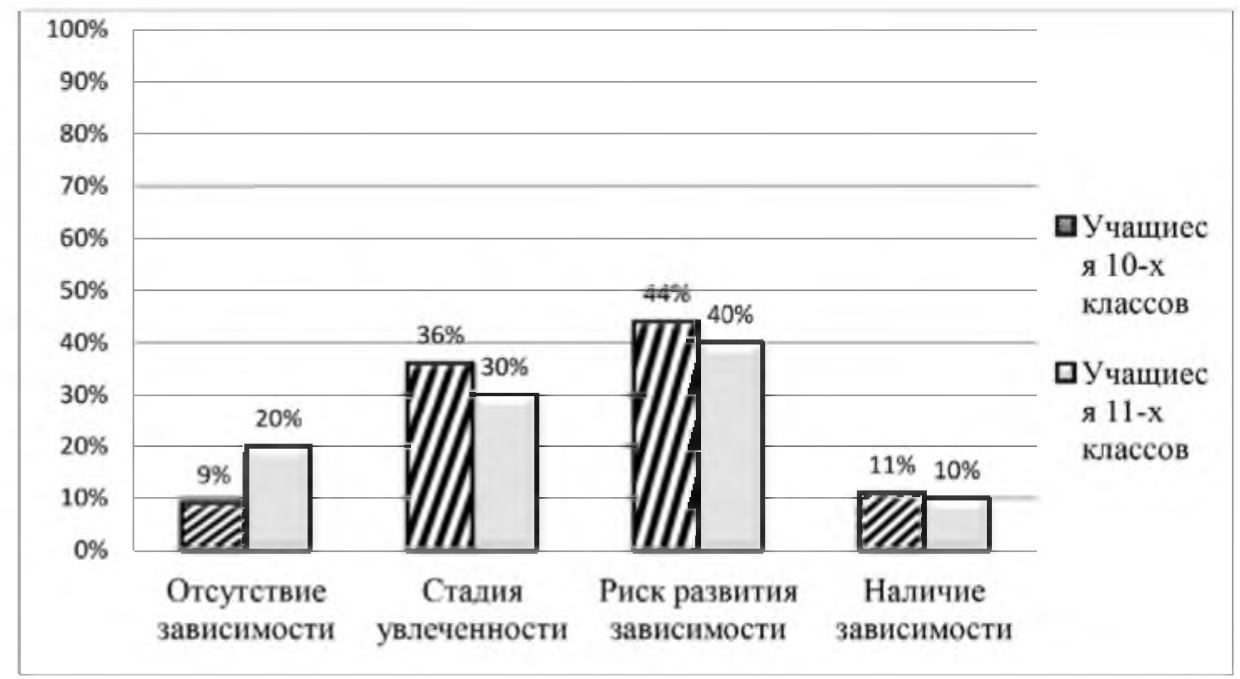

Рис. 1. Результаты проведения опроса «Скрининговая диагностика компьютерной зависимости» (Л. Н. Юрьева, Т. Ю. Больбот)

Исходя из представленных результатов опросника, большинство опрошенных подростков имеют риск развития компьютерной зависимости. Как правило, у подростка с развитием риска компьютерной зависимости начинаются проблемы с реальностью, нарушается социальная 
адаптация, ему становится трудно находить общий язык и общие темы с родителями, сверстниками и другими людьми. Многие социально значимые вещи, такие как учеба, семья перестают заботить. Происходит негативное влияние на бытовую, учебную, социальную, семейную сферы деятельности. Увлеченность компьютером может привести к равнодушию к окружающему миру.

Методика II. Тест Такера на выявление игровой зависимости направлен на выявление степени игровой зависимости подростка. Опросник содержит 9 вопросов, на которые подросткам предлагается ответить, учитывая последние 12 месяцев.

Обработка результатов проводится в соответствии с ключом. За каждый ответ начисляется от 0 до 3 баллов. Общая оценка подсчитывается путем суммирования баллов.

Согласно результатам Теста Такера на выявление игровой зависимости, было выявлено, что риск развития игровой зависимости имеют $32 \%$ учащихся 10 -х классов и $40 \%$ учащихся 11 -х классов. Подростки, имеющие риск игровой зависимости, все свое свободное время стремятся провести за компьютером, планшетом или телефоном, теряя интерес к другим занятиям. Они таюже теряют контроль над временем, проведенным за экраном гаджетов.

Наличие негативных последствий от игры характерно для 36 \% учащихся 10 -х классов и $32 \%$ учащихся 11-х классов. У учащихся, имеющих негативные последствия от компьютерных игр, заметен эмоциональный подъем, который резко и без причин сменяется плохим настроением, иногда с применением агрессии. Происходит утрата контакта с родителями, подростки начинают избегать доверительных разговоров, начинают обманывать.

Высокая вероятность патологического формирования зависимости от игровой деятельности за компьютером наблюдается у $9 \%$ учащихся 10 -х классов и 8 \% учащихся 11 -х классов. Для таких подростков характерно:

- обстоятельные аномалии от нормы в поведении, реакциях;

- неадекватность;

- отсутствие эмоционального и поведенческого самоконтроля;

- отсутствие аппетита;

- получает удовольствие, только играя в компьютерную игру или проводя время в Интернете, и т. д.

Обобщенные результаты диагностики игровой зависимости подростков представлены на рис. 2.

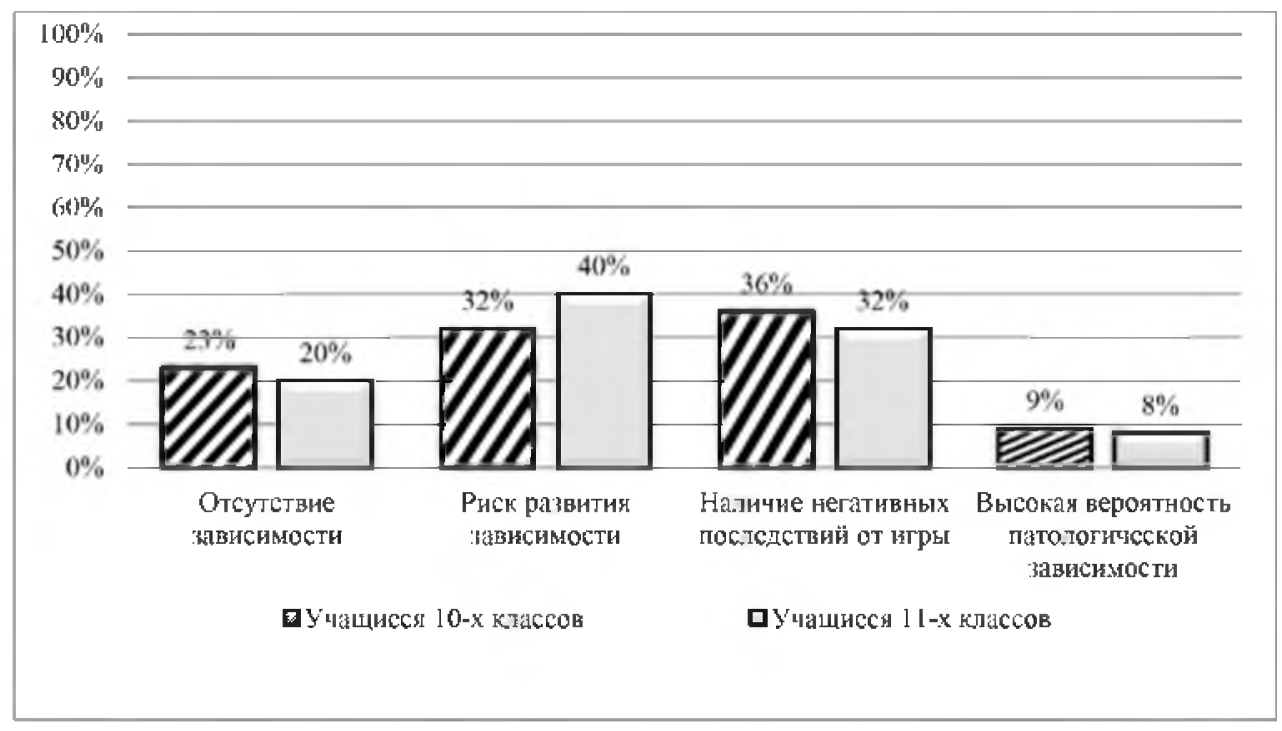

Рис. 2. Результаты Теста Такера на выявление игровой зависимости 
На основании представленных результатов опросника большинство опрошенных подростков имеют риск развития игровой зависимости, а также негативные последствия от чрезмерного увлечения компьютерными играми. Такие подростки эмоционально не уравновешены, становятся тревожными и подвержены депрессивному состоянию, им сложно найти общий язык со своими сверстниками.

Методика III. Оценка уровня общительности (В. Ф. Ряховский) способствует выявлению уровня сформированности общения у подростков. Методика содержит 16 вопросов, на которые подростки должны ответить «Да», «Нет», «Иногда». По окончании диагностики подсчитываются полученные очки, суммируются и по классификатору определяется, к какой категории людей относится испытуемый. Суммарный показатель варьируется от 0 до 32 баллов:

- 3 очка и менее - коммуникабельность носит болезненный характер;

- $\quad$ 4-8 очков - открыт для общения;

- 9-13 очков - весьма общителен;

- $\quad$ 14-18 очков - нормальная коммуникабельность;

- $\quad$ 19-24 очков - в незнакомой обстановке чувствуете себя вполне уверенно;

- 25-29 очков - замкнуты, неразговорчивы;

- 30-32 очка - Вы явно некоммуникабельны.

Оценка уровня общительности В. Ф. Ряховского позволила выявить уровень общительности учащихся университетских профильных классов Педагогического института. Согласно диагностике, открытыми для общения и весьма общительными оказались 13 \% учащихся 10 -х классов и $15 \%$ учащихся 11-х классов. Такие подростки всегда в курсе всех дел. Они любят принимать участие во всех дискуссиях, всюду чувствуют себя уверенно, охотно знакомятся с новыми людьми.

Обобщенные результаты диагностики уровня общительности подростков представлены на рис. 3.

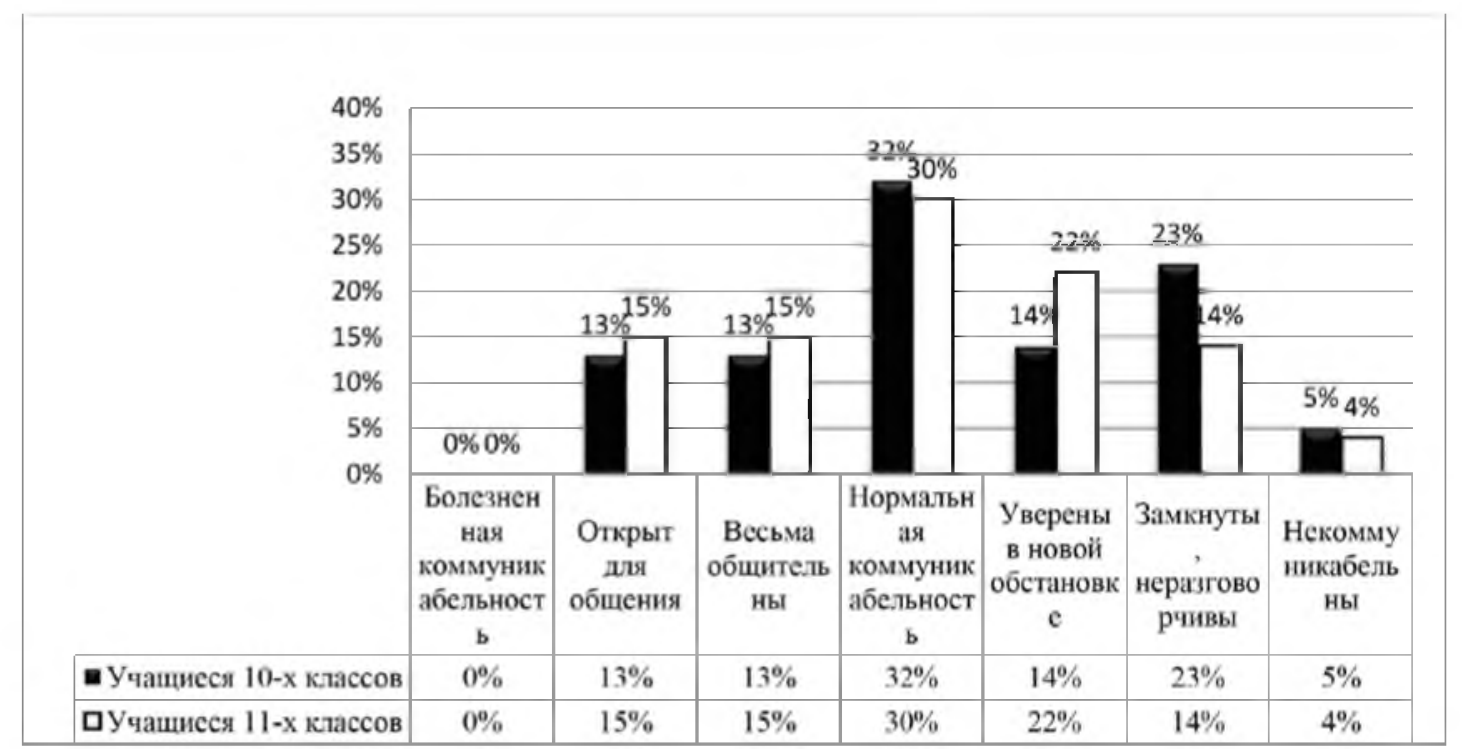

Рис. 3. Результаты Оценка уровня общительности (В. Ф. Ряховский)

Проведенная диагностика по выявлению уровня общительности обучающихся показала, что большинство учашихся имеют нормальную коммуникабельность. Они с интересом слушают собеседника, в общении с другими людьми проявляют достаточные терпеливость, внимательность, умеют спокойно и без конфликтов отстаивать свою точку зрения. Однако следует отметить, что $19 \%$ от общего числа опрошенных замкнуты и неразговорчивы, а 4 \% опрошенных имеют проблемы с коммуникабельностью, что указывает на наличие проблем с социальной адаптацией. 
Методика IV. Опросник уровня агрессивности Баса - Дарки направлен на выявление уровня агрессии у подростков. Опросник содержит 75 утверждений закрытого типа. Респонденту предлагается оценить степень своего согласия / несогласия с каждым из них.

Данная методика позволила исследовать выраженность различных видов агрессии у испытуемых. Ниже будет показано процентное соотношение показателей в среднем по группе (см. рис. 4).

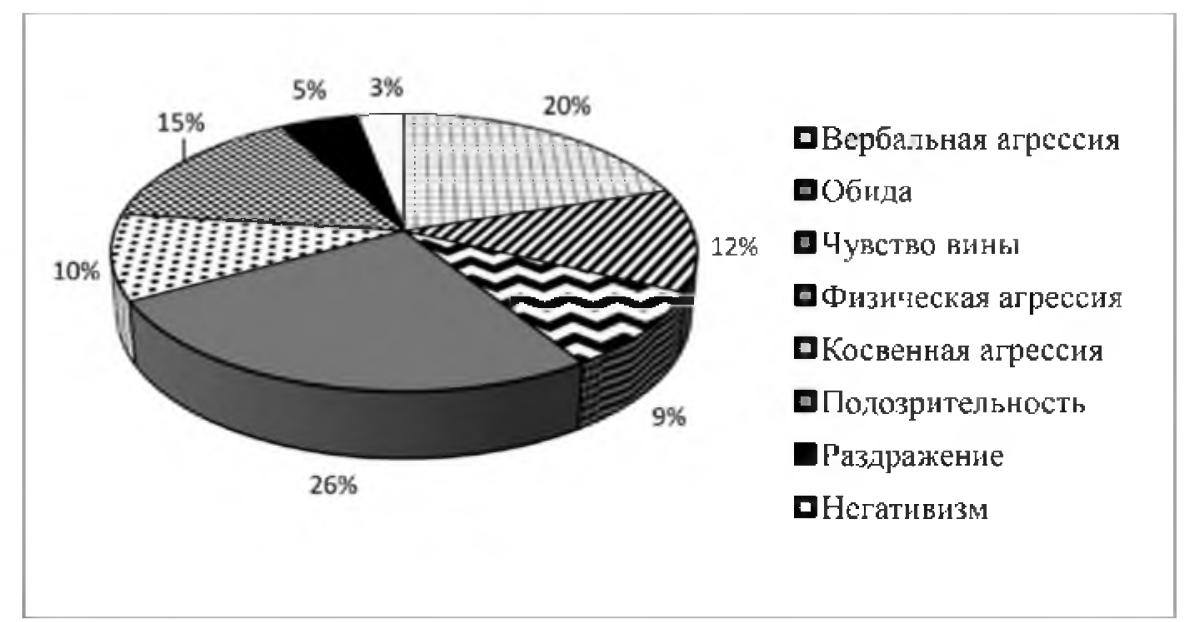

Рис. 4. Результаты диагностики по Опроснику уровня агрессивности Баса - Дарки

Из диаграммы видно, что наибольшее количество баллов по всей группе набрали такие показатели, как физическая и вербальная виды агрессии, а меньше всего у подростков выражен негативизм. Свои негативные чувства выражают через ссоры, крики, визги, а также через словесную брань. Используют физическую силу против другого лица. Часто проявляются взрывы ярости.

Подводя итог, хочется отметить, что результаты диагностики показали наличие у опрошенных подростков следующие проблемы:

- наличие риска развития компьютерной зависимости;

- наличие риска развития игровой зависимости, а также негативные последствия от чрезмерного увлечения компьютерными играми;

- $\quad$ наличие проблем коммуникативного характера;

- наличие у подростков физической и вербальной агрессии.

Заключение / Conclusion. Работа за компьютером, внедрение Интернета или некоторых видеоигр является в какой-то мере полезной для развития различных способностей человека. Почти все компьютерные игры могут быть информативными, а в Интернете можно найти много нужной и увлекательной информации, но только когда время, проведенное за компьютером, не сильно длительное, так как в противном случае может появляться патологическая подневольность и надобность оставаться с компьютером больше времени.

Компьютерозависимый человек становится менее дружелюбным, неискренним, некоммуникабельным. При ярко выраженной компьютерной зависимости наблюдается мощная деградация социальных связей личности и дезадаптация человека.

\section{ЛИТЕРАТУРА И ИНТЕРНЕТ РЕСУРСЫ}

1. Абраменкова В. В. Социальная психология детства: развитие отношений ребенка в детской субкультуре / В. В. Абраменкова. - Москва, 2010.

2. Алешина Ю. Е. Индивидуальное и семейное психологическое консультирование / Ю. Е. Алешина. Москва, 1999. 
3. Андреева О. С. Особенности представлений о коммуникации у студентов, зависимых от социальных сетей / О. С. Андреева, Е. С. Андреев // Вестник Тюменского государственного университета. - 2009 - № 5.

4. Божович Л. И. Личность и ее формирование в детском возрасте : учебно-методическое пособие / Л. И. Божович. - Москва : Просвещение, 1995.

5. Гордеева А. В. Увлеченность компьютерными играми: психологический аспект / А. В. Гордеева. Киев, 2014.

6. Егоров А. Ю. Нехимические зависимости / А. Ю. Егоров. - Санкт-Петербург : Речь, 2007.

7. Короленко Ц. П. Аддиктивное поведение. Общая характеристика и закономерности развития / Ц. П. Короленко // Обозрение психиатрии и медицинской психологии. - 1991. - № 1.

8. Куликов Л. В. Психогигиена личности. Вопросы психологической устойчивости и психопрофилактики: учеб. пособие / Л. В. Куликов. - Санкт-Петербург : Питер, 2004

9. Налчаджян А. А. Социально-психологическая адаптация личности / А. А. Налчаджян. - Ереван, 1988.

10. Смирнова Ю. С. Факторы межличностной аттракции в различных видах интернет-коммуникации / Ю. С. Смирнова, В. А. Чумакова // Психологический журнал. - 2012. - № 3, 4.

11. Худяков А. В. Компьютерная игровая зависимость, клиника, динамика и эпидемиология / А. В. Худяков, А. В. Урсу, А. М. Старченкова // Медицинская психология в России: электронный научный журнал. - 2015. - № 4 (33).

\section{REFERENCES AND INTERNET RESOURCES}

1. Abramenkova V. V. Social'naya psihologiya detstva: razvitie otnoshenij rebenka v detskoj subkul'ture / V. V. Abramenkova. - Moskva, 2010.

2. Aleshina YU.E. Individual'noe i semejnoe psihologicheskoe konsul'tirovanie / YU. E. Aleshina. - Moskva, 1999.

3. Andreeva O. S., Andreev E. S. Osobennosti predstavlenij o kommunikacii u studentov, zavisimyh ot social'nyh setej (Peculiarities of communication concepts among students depending on social networks) / O. S. Andreeva, E. S. Andreev // Vestnik Tyumenskogo gosudarstvennogo universiteta. -2009. - No 5.

4. Bozhovich L. I. Lichnost' i ee formirovanie v detskom vozraste. Uchebno-metodicheskoe posobie / L. I. Bozhovich. - Moskva : Prosveshchenie, 1995.

5. Gordeeva A. V. Uvlechennost' komp'yuternymi igrami: psihologicheskij aspect / A. V. Gordeeva. - Kiev, 2014.

6. Egorov A. YU. Nehimicheskie zavisimosti / A. YU. Egorov. - Sankt-Peterburg : Rech', 2007.

7. Korolenko C. P. Addiktivnoe povedenie. Obshchaya harakteristika i zakonomernosti razvitiya / C. P. Korolenko // Obozrenie psihiatri i imedicinskoj psihologii. - 1991. - № 1 .

8. Kulikov L. V. Psihogigiena lichnosti. Voprosy psihologicheskoj ustojchivosti i psihoprofilaktiki: ucheb. Posobie / L. V. Kulikov. - Sankt-Peterburg : Piter, 2004.

9. Nalchadzhyan A. A. Social'no-psihologicheskaya adaptaciya lichnosti / A. A. Nalchadzhyan. - Erevan, 1988.

10. Smirnova YU. S. Faktory mezhlichnostnoj attrakcii v razlichnyh vidah internet-kommunikacii / YU. S. Smirnova, V. A. CHumakova // Psihologicheskij zhurnal. - 2012. - No 3, 4.

11. Hudyakov A. V. Komp'yuternaya igrovaya zavisimost', klinika, dinamika i epidemiologiya / A. V. Hudyakov, A. V. Ursu, A. M. Starchenkova // Medicinskaya psihologiya v Rossii: elektronnyi nauchnyi zhurnal. - 2015. - No 4 (33).

\section{СВЕДЕНИЯ ОБ АВТОРАХ}

Куликова Яиа Александровна, кандидат педагогических наук, доцент кафедры кадрового управления, ФГБОУ ВО «Тамбоовский государственный университет имени Г. Р. Державина», г. Тамб́ов. E-mail: kulikowa.ya2014@yandex.ru

Пенькова Татьяна Алексеевна, ассистент кафедры профильной довузовской подготовки ФГБОУ ВО «Тамбовский государственный университет имени Г. Р. Державина», г. Тамбов. E-mail: tatyana.penykova $a$ yandex.ru

\section{INFORMATION ABOUT AUTHORS}

Yana Kulikova, Candidate of Pedagogical Sciences,Associate Professor of the Department of Personnel Management, Federal State Budget Educational Institution of Higher Education «Tambov State University named after G. R. Derzhavin», Tambov. E-mail: kulikowa.ya2014@yandex.ru

Tatyana Penkova, assistant of the Department of pre-University profile training Federal State Budget Educational Institution of Higher Education «Tambov State University named after G. R. Derzhavin», Tambov. E-mail: tatyana.penykova@yandex.ru 